\title{
LA DEMOCRATIZACIÓN DE LA CULTURA Y LA SOCIALIZACIÓN DEL CONOCIMIENTO EN UN CONTEXTO DE CRISIS
}

\section{THE DEMOCRATIZATION OF CULTURE AND THE SOCIALIZATION OF KNOWLEDGE IN A CONTEXT OF CRISIS}

\author{
Juan Antonio García Galindo \\ (Universidad de Málaga) \\ jagarciag@uma.es
}

Recibido: 4 de enero 2021 / Aceptado: 25 de febrero 2021

\begin{abstract}
Resumen: Sin duda, hay una relación estrecha entre el uso social de las tecnologías de la información y de la comunicación -especialmente de las tecnologías móviles- y la democratización de la cultura -tanto en los procesos de producción como de recepción-, en el sentido de extensión y de apropiación de la misma. Sin embargo, quizás sea más apropiado vincular dicho concepto al de socialización de la cultura, en su acepción relativa a la capacidad de los ciudadanos para acceder activamente a ella, como consumidores críticos, pero también como emisores y productores. Por su parte, el concepto democratización implicaría en todo momento el acceso igualitario a la cultura y el aprovechamiento por igual del potencial de las tecnologías para convertir a la ciudadanía en emisores y productores de contenidos y de mensajes de todo tipo (periodísticos, literarios, artísticos, textuales, icónicos, etc.). Entre otras cosas, porque en la sociedad digital las brechas sociales, económicas, o propiamente intelectuales también siguen existiendo. Si la democratización de la cultura es posible en toda la extensión de su significado será porque sepamos integrar, o no, las nuevas tecnologías digitales que se desarrollan en nuestro entorno en proyectos que reviertan en el enriquecimiento cultural de la ciudadanía y en la mejora de las condiciones de acceso, eliminando las brechas existentes. Y podamos dar pasos en la consecución de una sociedad culta que descanse sobre los principios éticos y los valores de toda sociedad democrática. Pero, aunque sea un objetivo inaplazable, no debería bastar con el acceso generalizado a la cultura, que es la base para que ésta sea democrática, sino con promover un tipo de ella que contribuya asimismo a la democratización de la sociedad.
\end{abstract}

Palabras clave: cultura, democracia, sociedad digital, conocimiento, tecnologías de la información y de la comunicación, comunicación social. 
Abstract: There is undoubtedly a close relationship between the social use of information and communication technologies, especially mobile technologies, and the democratisation of culture (in both production and reception processes), in the sense of extending culture and its appropriation. However, it is perhaps more appropriate to link this concept to the socialisation of culture, as it relates to citizens' capacity to actively access culture, as critical consumers, but also as producers and issuers. The concept of democratisation, on the other hand, would imply egalitarian access to culture at all times and taking equal advantage of the potential of technologies to turn citizens into issuers and producers of all kinds of contents and messages (journalistic, literary, artistic, textual, iconic, etc.). One of the reasons for this is that in the digital society, social, economic and intellectual divides also continue to exist. If the democratisation of culture is possible to the full extent of its meaning, it will be because we either know or we don't know how to incorporate the new digital technologies that are developing in our setting into projects that result in the cultural enrichment of all citizens and the improvement of the conditions surrounding access to culture, thereby eliminating the existing gaps. It should also enable us to take steps towards achieving a cultured society, based on the ethical principles and values of any democratic society. However, although this is a pressing objective, it should not be considered sufficient just to provide generalised access to culture, which is the basis for it to be considered democratic, but rather to promote a culture that also contributes to the democratisation of society.

Key words: culture, democracy, digital society, knowledge, information and comunication technologies, social communication.

\section{Introducción}

En 2002, tres de los investigadores latinoamericanos de mayor reputación, Jesús Martín Barbero, Raúl Fuentes Navarro y Teixeira Coelho, exponían sus puntos de vista sobre la democratización de la cultura en la revista mexicana Renglones, poniendo de relieve las principales características que debe reunir dicho proyecto. Para Martín Barbero, la cultura había de servir a la integración social y no a la exclusión, contribuyendo a conformar una pedagogía de convivencia en el espacio público. En esa tarea, la ciudadanía y los agentes culturales debían ser un factor importante en la construcción de comunidad desde la cultura (2002, 123). Raúl Fuentes, por su parte, ponía el énfasis en el derecho cultural como base de la democratización y la modernización de la sociedad; y en la ciudadanización como eje de la política estatal. Y añadía que era necesario repensar la relación entre la acción y las políticas institucionales en cuanto a la cultura y a la democracia (Fuentes, 2002, 124). Para Teixeira 
Coelho, la democratización de la cultura pasa por el diálogo entre lo público y lo privado (2002, 126). Este diálogo se sostiene sobre los propios fundamentos de la democracia. Escribe Raúl Fuentes que «la democracia es un formato de las relaciones sociales que tiene sus reglas, sus códigos y su gran espacio para la creatividad en términos de conversación» $(2002,126)$. Poco ha cambiado desde entonces, y escasa sigue siendo la apreciación de la cultura como fundamento de la democracia a la que, a su vez, realimenta. Bajo el espejismo de la tecnología se han olvidado otros discursos igualmente necesarios, y aún seguimos esperando que las políticas institucionales se acuerden de la cultura, otorgándole definitivamente la importancia que se merece.

Las tecnologías por sí mismas no solucionan los grandes problemas del mundo; sino que hay que dotarlas de sentido e integrarlas adecuadamente en los procesos de formación, de información, de investigación, de producción o de creación, sabiendo para qué las utilizamos y con qué objetivos, y evaluando posteriormente sus resultados. La euforia tecnológica que vivió la sociedad a comienzos del presente siglo dio lugar a posicionamientos teóricos, educativos e incluso políticos que consideraban que la mera introducción de la tecnología en esos procesos induciría casi automáticamente resultados positivos y resolutivos. Se trataba, en cualquier caso, de una simplificación, entre otras cosas porque el conocimiento y la cultura, como otros órdenes de la existencia, son fenómenos complejos en los que intervienen las personas y donde las máquinas siguen siendo, por el momento, intermediarias y complementarias de los proyectos. Quizás con el desarrollo de la Inteligencia Artificial (IA) estemos asistiendo a un cambio de paradigma, verdaderamente revolucionario, que puede estar situándonos ante un nuevo escenario tecnocultural de posibilidades extraordinarias (Rodríguez Ortega, 2020, 32) ${ }^{1}$.

\section{La transformación de la cultura: los nuevos escenarios}

\footnotetext{
1 «El desarrollo de sistemas de IA (Inteligencia Artificial), con los que convivimos diariamente, ha reforzado, a su vez, el descentramiento -teórico y fáctico- del que viene siendo objeto el ser humano desde hace décadas, abocado ahora a coexistir con dispositivos no humanos involucrados en la producción de conocimiento y en procesos creativos». Rodríguez Ortega, Nuria (2020): Inteligencia Artificial y campo del arte. Paradigma, 23, p.32.
} 
«La palabra cultura -escribe Sassoon- es un término extraño y lleno de implicaciones» (2006, 4). En su acepción más amplia, antropológica ${ }^{2}$, la cultura experimenta en la actualidad numerosos cambios provocados por factores muy diversos que, como en cualquier otra época histórica, convergen en el espacio y en el tiempo creando el contexto idóneo para que éstos fragüen. Asistimos, con toda probabilidad, al final de una larga transición cultural -en el sentido de civilización- que comienza tras la posguerra mundial durante los años cincuenta del pasado siglo, con el desarrollo de la sociedad de consumo de masas, heredera de la irrupción de estas en la vida pública y del nuevo papel de los intelectuales y artistas que había tenido su exponente en los años veinte y treinta, y que coincide con el desarrollo de los medios masivos de información y de comunicación. Ortega y Gasset (1930) definió precisamente como «rebelión de las masas» la emergencia de éstas en la vida pública; y su aparición allí donde antes solo estaban las minorías. Lo que autores recientes como Jesús Timoteo Álvarez (1987 y 2012) o Josep Lluís Gómez-Mompart (1992) han confirmado desde la perspectiva de la comunicación social. En su obra sobre la génesis de la sociedad de consumo de masas en Cataluña, Gómez-Mompart puso de relieve los factores que la hicieron posible y que, a su vez, pudimos comprobar también para otras regiones y territorios de España, como es el caso de Andalucía (García Galindo, 1995).

Los factores que han inducido la transformación de la cultura en la actualidad no son exactamente los mismos que apuntábamos para el primer tercio del siglo XX; hay que salvar las distancias obvias, pero algunos factores se repiten por la influencia siempre permanente que el crecimiento demográfico, el desarrollo urbano y las tecnologías aplicadas a la comunicación tienen, entre otros, sobre la cultura y sobre los medios de masas. Entre otros factores actuales señalaremos los siguientes: a) la urbanización creciente y el desarrollo de las ciudades; b) la inmigración masiva y la multiculturalidad; c) la globalización económica y la mundialización; d) el desarrollo de las TIC y la implantación de la sociedad digital; e) los nuevos medios de comunicación; f) la crisis de las potencias tradicionales y el paso de un mundo bipolar a otro multipolar; g) la crisis de las democracias occidentales; h) el papel diluido del individuo en las sociedades actuales; i) la pérdida de valores y de referentes sociales; j) la crisis de la educación; k) la crisis del periodismo; etc. Factores, como vemos,

\footnotetext{
2 «En la lengua hablada actual se utiliza principalmente en el sentido antropológico sugerido en 1871 por Edward Burnett Tylor en su Primitive Culture: La cultura o civilización, entendida en el amplio sentido etnográfico de la palabra, es un todo complejo que abarca el conocimiento, las creencias, el arte, la moral, el derecho, las costumbres y cualquier otra competencia y hábito que haya adquirido el hombre en tanto que miembro de una sociedad». Sassoon, Donald (2006): Cultura. Elpatrimonio común de los europeos. Barcelona: Crítica, p. 4.
} 
muy diversos, a los que ha venido a sumarse un acontecimiento súbito e inesperado que ha marcado ya para siempre la historia contemporánea de la humanidad: la pandemia del Covid19 que, desgraciadamente, ha provocado, hasta el momento, casi dos millones de muertos en todo el mundo y que sigue confinando a la población mundial en sus hogares; una situación que no solo ha provocado el colapso sanitario que padecemos sino también una crisis económica que ya tiene una gran repercusión sobre las economías de las grandes potencias, desplazando los centros de poder mundiales desde Estados Unidos y Europa al eje euroasiático compuesto por China y Rusia.

Todos estos cambios han dado lugar a un nuevo escenario social, político, económico y tecnológico que genera una nueva cultura, al tiempo que, a su vez, esta provoca cambios, sobre su contexto. Estos cambios se están produciendo cada vez más rápidamente debido a la gran aceleración histórica que hoy vive el mundo por los numerosos acontecimientos que se vienen sucediendo. Entre los años iniciales del siglo XXI y la actualidad han transcurrido dos décadas durante las cuales se ha ido transformando la idea de progreso y de desarrollo. Desde una visión de la globalización y de las tecnologías, que preconizaba la solución definitiva a los grandes problemas del mundo, hemos pasado en la actualidad a una crisis profunda de las estructuras supranacionales y al repliegue sobre sí mismas de las naciones, en una especie de proceso inverso que permite relativizar el sentido y la naturaleza de la globalización, y nos debe hacer pensar igualmente sobre el control de las nuevas tecnologías como instrumentos necesarios pero que deben estar al servicio de la sociedad antes que del mercado, y cuya finalidad social garantice un uso responsable y no excluyente.

Quizás el corto siglo XX que, según los historiadores, comenzó de facto tras la Primera Gran Guerra, y que acabó tras la desaparición de la antigua URSS, esté cerrándose en realidad en estos momentos con el declive de la gran potencia americana y el auge de China; y que en la actual crisis económica provocada por la pandemia se encuentre la ruptura definitiva con el antiguo orden mundial derivado de la Segunda Gran Guerra. La Historia no es caprichosa y está plagada de razones que los historiadores deben desvelar. Si el metarrelato de la globalización neoliberal -hasta ahora dominante- ha entrado en crisis por los cambios en los equilibrios internacionales y por la nueva geopolítica mundial, es muy probable que estemos asistiendo igualmente a una resignificación semántica de la noción de globalización en un mundo con nuevas hegemonías, que no son solo económicas y comerciales sino también políticas y culturales. En ese nuevo equilibrio mundial, el papel que desempeñe la Unión Europea, ahora sin Reino Unido, si es capaz de ejecutar políticas viables de cohesión, puede ser fundamental para preservar los valores de la cultura que mejor pueden 
representarnos. Porque será en el control del relato donde se resuelvan muchos de los conflictos ideológicos, políticos y culturales del mundo de hoy, en una sociedad mediada e interconectada como es la actual. El papel de los historiadores y de los agentes de la cultura será fundamental en el proceso de resistencia que evite la colonización cultural y procure, en cualquier caso, la existencia de procesos de hibridación y de mestizaje no coloniales que sean producto de la libertad de expresión y de creación. Para ello es vital que los grandes medios, que siguen ejerciendo una gran influencia en la opinión pública -ya sea a través de sus ediciones impresas, audiovisuales o digitales- se posicionen del lado de la ciudadanía y de la democracia, a las que se deben.

A comienzos del presente siglo, los profesores Juan José Carreras y Carlos Forcadell afirmaban que no faltan historiadores que « construyen y reformulan propuestas sólidas de recuperar la fundamentación y la historia de la democracia » frente a la globalización neoliberal (2002, 41); sin embargo, en la actualidad, los historiadores, y en general los intelectuales, han sido relegados más que nunca a un papel de segundo orden, atribuyendo, por el contrario, el liderazgo en la opinión pública a las élites de la política y del periodismo. Corresponde, pues, a los intelectuales y a los artistas recuperar el espacio perdido, promoviendo una cultura democrática que sea a su vez democratizadora y transformadora del entorno, y que no lo sea solo formalmente.

\section{Las sociedades democráticas como objetivo}

Definir una sociedad por la tecnología es un recurso cuando menos impreciso, por no decir insuficiente. Entre otras cosas, porque la aparición y desarrollo de un nuevo sistema tecnológico no siempre trae consigo la modificación de las estructuras sociales, políticas o económicas que sus defensores a ultranza le suponen. En ocasiones, esas transformaciones transcurren en medio de sistemas políticos y sociales que no se corresponden con las nuevas demandas tecnoproductivas. Hasta que no se ha generalizado un nuevo medio de producción no se producen los grandes cambios sociales y políticos; y no siempre de manera previsible. La concatenación entre las revoluciones industriales de los siglos XVIII, XIX y XX, junto al crecimiento demográfico, el éxodo rural, el desarrollo del capitalismo y las revoluciones burguesas y nacionales, son fenómenos que solo podemos entender en perspectiva histórica. Los instrumentos de la cultura siempre han sido las tecnologías, por muy rudimentarias que estas hayan sido. Pero, por encima de ello, se halla la mente humana y su voluntad de crear; así como, el uso decidido de determinadas herramientas con las que interactuar para innovar. 
Para Gordon Childe, en la dualidad mano-cerebro, merced a la complejidad del sistema nervioso del cerebro humano, se encuentra la capacidad para la creación y, a su vez, para el desarrollo del lenguaje oral y de otros lenguajes expresivos; la interacción entre ambos se produce gracias al uso de la tecnología. Sin duda, el manejo de la misma contribuyó, entre otros factores, a la evolución de la mente en el origen de la especie humana (Childe, 1995, 38-39).

Utilizada por prehistoriadores y antropólogos para denominar a determinadas fases de la Prehistoria, cuando aún no había una organización social clara (paleolítico, neolítico, etc.), la tecnología, sin embargo, es un recurso que en la actualidad se utiliza también con el fin de no transparentar otras facetas de la realidad histórica. La sociedad de la información y del conocimiento, o la sociedad digital, son denominaciones que no definen a las sociedades ni por su estructura de clases ni por quien detenta los medios de producción o controla el poder. No es lo mismo hablar de sociedad estamental o de sociedad burguesa que de sociedad digital o de sociedad de la información, que tratan de definir a la sociedad -la nomenclatura es muy importante- a través de características supuestamente transversales y por determinadas tecnologías que eluden de todo discurso la referencia a la posición económica de los ciudadanos y a la dinámica del poder. Por ello, dado que no existe una relación clara entre la etiqueta tecnológica y la defensa de los derechos humanos, quizás sea preferible hablar de sociedades democráticas, o no, concepto que sitúa el derecho universal en el centro de la taxonomía histórica. ¿Son democráticas las sociedades digitales? O simplemente confundimos la generalización del acceso a las tecnologías con la democratización de la sociedad.

\section{Información vs. conocimiento. Por una cultura democratizadora}

La infoxicación de la que hablaba Toffler en los años setenta del pasado siglo, en referencia al aumento de los canales de información y de la presión informativa sobre los ciudadanos ${ }^{3}$, era además una consecuencia directa del amarillismo y del sensacionalismo periodístico del siglo XIX que habían representado Hearst y Pulitzer. Toffler ya anunciaba un fenómeno que no ha hecho sino expandirse en paralelo al desarrollo de los medios de comunicación hasta la actualidad. Siendo Internet y los medios digitales el final, por el momento, de un mismo

\footnotetext{
3 Vid. Toffler, Alvin [1970] (1995): El shock del futuro. Barcelona: Plaza y Janés. Este libro fue publicado por primera vez en 1970. En él Toffler utiliza exactamente la expresión «sobrecarga de información difícil de procesar» (information overlead), que Alfons Cornella ha traducido como infoxicación, término acuñado y aceptado en castellano para denominar la saturación de la que hablaba Toffler.
} 
eslabón. Paradójicamente, en plena sociedad de la información y del conocimiento -términos que no podemos desligar de su acepción económica- abundan los rumores, la manipulación, la desinformación y las noticias falsas. Además, tiene lugar una crisis añadida de la escuela, que ya dura muchos años, a la que le cuesta encontrar su sitio en la sociedad actual sin renunciar a los valores que la deben caracterizar.

Para Ángel Pérez Gómez, no es objetivo de la escuela actual seguir acumulando más información sino ayudar a la ciudadanía a convertirse en personas educadas y a seleccionar aquella información que le sirva para construir sus propios proyectos personales, sociales o profesionales. Se trata, añade este autor, de transformar la información en conocimiento y el conocimiento en sabiduría, pese a la dificultad de un contexto caracterizado por la saturación de la información y la incertidumbre (cfr. Pérez Gómez, 2012). Desde nuestro punto de vista, habría que añadir que la escuela, en tanto institución educativa, está obligada a una permanente actualización de sus contenidos y, por tanto, debe -ayudada por la ciencia- seguir incorporando al currículum escolar los avances que se vayan produciendo y se hayan verificado, siempre de un modo crítico y contrastado. Sobre todo, porque así será más fácil alcanzar los objetivos que el citado autor propone.

Precisamente, en la Era de la Información, la transparencia es opaca y la incertidumbre generalizada. En este contexto, el individuo está indefenso porque los sistemas democráticos, envueltos en las crisis que los acosan, se olvidan con frecuencia de él. Y éste es el principal síntoma de la crisis de la democracia. Por eso mismo, tampoco debe bastar una cultura que sea democrática, principal aspiración en las sociedades donde rigen los derechos humanos, sino una cultura que contribuya asimismo a la democratización de la sociedad. Porque, ¿puede existir una cultura democrática en una sociedad que no lo es? ¿O que solo lo es formalmente? No basta, en suma, con contar con las instituciones necesarias para la organización y el funcionamiento de una sociedad democrática, lo verdaderamente importante es que el funcionamiento de esas instituciones sea democrático.

\section{Las culturas de la cultura digital}

El desarrollo de los medios de comunicación y de las TIC han favorecido la ruptura de la brecha infranqueable en otros tiempos entre la cultura de élite y la cultura popular, estableciendo nuevos vasos comunicantes entre ellas, y provocando la ruptura de ese binomio a favor de nuevos fenómenos culturales, que se construyen en función de la procedencia del hecho cultural y de sus espacios de desarrollo; y que pueden coexistir, pero 
que se repliegan o no en función de los modelos sociales y económicos dominantes. Desde que en 1951 Arnold Hauser publicara la primera edición de su Historia social de la literatura y el arte, se puso de relieve que la cultura en todas y cualquiera de sus manifestaciones ha de ser concebida como un producto social que no puede entenderse sino en su relación con el contexto, ya sea económico, político, religioso, social o tecnológico (cfr. Hauser, 2010). Asimismo, la implantación de sistemas sociales más abiertos y plurales ha favorecido la aparición de movimientos artísticos y culturales más transgresores y rupturistas, o que son procedentes de otros contextos geográficos que han dado lugar a ámbitos propios de influencia gracias sobre todo a la existencia de mayores espacios para la libertad creativa. Las TIC han abierto un nuevo espacio sin límites para el desarrollo de una cultura de todos para todos, que no está exenta de problemas y de controversias, y que está expuesta al mestizaje cultural, porque los fenómenos de copia e hibridación son extensos en el mundo virtual.

Sin duda, se han ampliado los límites en el acceso a la cultura, pero aún siguen existiendo (y creciendo) brechas digitales y específicamente culturales que existen por razón de educación, nivel económico, social, etc. No olvidemos tampoco que los grupos sociales se exponen a los productos culturales en función del grado de gratificación que reciben, y que esa compensación viene determinada a su vez por factores no solo endógenos, sino también exógenos.

Pese a ello, en las sociedades democráticas -caracterizadas asimismo por la mayor permeabilidad cultural- deberíamos apostar por una cultura que ponga el énfasis en el ciudadano como sujeto de derechos, y como centro y destino de la producción cultural. En definitiva, abogar por una cultura ciudadana, que permita articular otros procesos de construcción de la ciudad a través de la participación. El concepto de cultura ciudadana nos remite directamente a la democracia sobre la que se asienta la categoría de ciudadanos. En definitiva, una cultura que ponga al ser humano en contacto de forma holística con la cultura, y que promueva consumos culturales heterogéneos, que deberían estar unidos por el denominador común de la calidad y de la ética. Porque ser capaz de admirar y de reconocer el arte o la literatura no implica ser capaz de crear, y ser capaz de crear no es tampoco sinónimo de crear con calidad.

La globalización cultural, la pérdida de referentes locales y las nuevas prácticas comunicativas inducidas por las nuevas tecnologías nos permiten distinguir entre una producción cultural profesionalizada y otra amateur, resultado de la producción social. Advierte Ramón Zallo que «la eclosión de la cultura amateur gracias a la red y a los equipamientos locales es un plus 
que va más allá del nivel de las demandas culturales para contribuir a la socialización cultural, e incluso es pórtico para la creación profesionalizada» (Zallo, 2019, 43). Sin embargo, la cultura fragmentada que se deriva del uso de las redes dificulta precisamente la conversión de la información en conocimiento. Esta fragmentación inducida por el consumo individualizado de los contenidos que ofrecen las tecnologías de comunicación, y que a su vez se presentan igualmente de manera fragmentada, para atraer la atención de un usuario acostumbrado a recibir contenidos simples frente a contenidos complejos, y contenidos cortos frente a los largos.

La digitalización ha cambiado la distribución y difusión de los bienes simbólicos, y ha provocado cambios en los hábitos de consumo, que se han visto favorecidos por la aceleración y la inmediatez de los servicios. Asimismo, la digitalización ha hecho desaparecer algunas barreras en el fomento de la creatividad. La posibilidad de convertir a los usuarios de las tecnologías móviles en emisores y productores de contenidos y de propuestas literarias o artísticas ha creado un cierto espejismo, y una cierta confusión en el mundo de la cultura. En la medida en que las nuevas tecnologías de la información y de la comunicación posibilitan la creación y la difusión cultural se produce una interdependencia mayor con el ámbito comunicativo, e incluso se mezclan las tareas de las profesiones de la comunicación con las de los mediadores de la cultura.

\section{Un escenario de dificultades: las Industrias Culturales y Creativas entre crisis}

No podemos olvidar que la cultura y la educación van de la mano. Una sociedad más formada demandará productos de mayor calidad, y ello redundará positivamente en la actividad de los creadores. Además, el sector educativo -especialmente, de formación profesional y universitario- aporta a las Industrias Culturales y Creativas (ICC) un número elevado de egresados de esos niveles de la enseñanza.

Si hacemos una enumeración de las ICC más importantes, muchas de ellas van a ser resultado de los cambios tecnológicos, puesto que estos han favorecido el desarrollo de nuevos nichos de empleo: arquitectura; artes escénicas, artes visuales y cinematográficas; producción audiovisual y multimedia (música, videojuegos, etc.); bibliotecas, museos y patrimonio; libros y prensa; y publicidad ${ }^{4}$.

\footnotetext{
${ }^{4}$ Sobre la importancia de las ICC puede consultarse: Castro Higueras, Antonio (2017): Las Industrias Culturales y Creativas y su Indice de Potencialidad. Salamanca: Editorial Comunicación Social.
} 
Durante los años de la crisis económica anterior, en particular entre 2008 y 2014, las ICC experimentaron en la Comunidad Autónoma de Andalucía (García Galindo et al., 2017) ${ }^{5}$ un gran decrecimiento, situándose en 2014 en el $5 \%$ del volumen de negocio respecto al total nacional, por delante del País Vasco (con un 3,6 \%) y la Comunidad Valenciana (3,5 $\%$ ), pero muy por detrás de Madrid (con el 54,3\%) y Cataluña (22,4\%). No podemos pasar por alto que Andalucía es la comunidad más poblada de España.

Un repaso a la situación de las ICC en Andalucía nos proporciona la siguiente radiografía:

1. Los tres sectores que mayor volumen de negocio generaron en 2014 fueron por este orden: a) Libros y Prensa (25,1\%); b) Arquitectura (21,9\%), y c) Audiovisual y Multimedia (18,8\%).

2. Los que mayor número de empleados ocuparon fueron: a) Arquitectura (19,6\%), b) Publicidad (18,6\%), y c) Audiovisual y Multimedia (16,6\%).

3. Respecto al número de empresas: a) Arquitectura (32,1\%), b) Artes Visuales (27,7\%), c) Libros y Prensa (13,2\%).

A partir de 2014 la situación fue de lenta recuperación, hasta la crisis sobrevenida en la actualidad por el Covid-19, alcanzando en 2016 las cifras más relevantes. Según datos de la Consejería de Cultura para ese año, el tejido empresarial cultural de la comunidad lo constituían 29.728 empresas y un total de 58.819 empleos. Estas cifras suponían ya un incremento del $17 \%$ en el número de empresas y 10.000 puestos de trabajo en el ámbito cultural.

La importancia de la economía cultural y creativa en el conjunto de la economía de un territorio es, sin duda, cada vez mayor, y puede contribuir a la formación de sociedades más inclusivas, más cultas y creativas, y más sostenibles. La labor de la Junta de Andalucía, a través de su Agencia de Instituciones Culturales, de la Fundación AVA de la Corporación de la RTVA, del Foro Transfiere, del Polo Digital, PTA, del Observatorio de Industrias Culturales de Andalucía (que tiene el apoyo del Ministerio de Cultura), del Clúster de Empresarios de las Tecnologías de la Información y la Comunicación (ETICOM), del Proyecto Lunar de Andalucía Emprende, o de las universidades andaluzas, entre otras instituciones, han contribuido desde hace años a dinamizar las ICC en Andalucía. Sería necesaria una mayor coordinación entre las políticas que sobre esta materia ponen en marcha

\footnotetext{
5 Todos los datos que se presentan sobre las ICC en la Comunidad Autónoma de Andalucía durante el periodo 2008-2014 proceden de: García Galindo, Juan Antonio et al. (2017): Las industrias culturales y creativas en Andalucia: grandes datos. Barcelona: Portal Localcom
} 
Ayuntamientos, Diputaciones y Gobierno Autónomo con las actividades de esos organismos. Así como, poner de manifiesto la importancia que las universidades andaluzas tienen en el desarrollo de este ámbito por diversas razones de enorme importancia. Entre otras:

a) por la formación de los graduados y de los expertos que van a incorporarse al ámbito de las ICC (economistas, creadores audiovisuales, publicitarios, ingenieros de telecomunicaciones e informática, expertos en patrimonio, en turismo, documentalistas, arquitectos, etc.).

b) Por la transferencia de conocimiento al sector público y privado, a través de la $\mathrm{I}+\mathrm{D}+\mathrm{i}, \mathrm{y}$ de los proyectos europeos, o de otra índole. Es sabido que la mayor parte de la investigación se lleva a cabo en España en las universidades públicas.

c) Por las acciones de emprendimiento y de empleabilidad que realizan las universidades destinadas a las ICC. Y, por la relación cada vez más estrecha entre el mundo empresarial y el universitario. La apuesta de las universidades por el emprendimiento y la empleabilidad está dando excelentes resultados.

En todo caso, la apuesta de un territorio por las ICC es una tarea de todos los agentes que intervienen en ellas. Lo que hagamos con la cultura, y con las industrias asociadas, tendrán siempre su reflejo sobre el territorio.

El Informe sobre el Estado de la Cultura en España para el año 2019, que coordina Enrique Bustamante, mostraba un panorama heterogéneo desde el punto de vista territorial, pero alentador y de repunte en los años finales de la crisis económica anterior (especialmente 2014-2016); sin embargo, las circunstancias actuales han parado en seco un desarrollo que ofrecía un escenario dinámico, aunque de lento crecimiento. Habrá que esperar a conocer con detalle el impacto que sobre las ICC en España tiene la pandemia para evaluar con rigor el estado actual de la situación, y vislumbrar pese a la incertidumbre generalizada las salidas a la postergación cultural que vivimos. Quizás esa evaluación nos depare un panorama muy desigual, con escenarios locales muy distintos, producto de las brechas territoriales ya existentes y de la diferente respuesta que las sociedades y el tejido local está dando en el plano cultural frente a la paralización del sector. Estas desigualdades locales y regionales en el Estado español, polarizadas desde mucho tiempo atrás en el mayor peso cultural de ciudades como Madrid y Barcelona, están dando paso a la atomización cultural de España por la acción de las diferentes políticas culturales y comunicativas de los gobiernos autonómicos, y especialmente por el mayor o menor dinamismo de las sociedades civiles locales, 
desplazándose hacia la periferia muchas de las iniciativas culturales de ámbito nacional. El dilema centro-periferia no tiene mucho sentido en un estado autonómico como el español, aunque haya sido una constante el predominio y la vanguardia de las actividades desarrolladas en la capital del Estado y en la ciudad condal; asimismo, el desarrollo demográfico del cinturón costero español ha roto definitivamente el predominio del centro sobre la periferia, atribuyendo a las ciudades más importantes un mayor peso en la distribución de las ICC.

Escribe López Garrido que «la cultura es el oxígeno de la mentalidad y estilo de vida de un país» $(2019,9)$, por eso su nacimiento y desarrollo están imbricados con el tejido local, donde también permanece lo cosmopolita, lo diverso, porque en lo local se sintetizan también las influencias que vienen de fuera. Y porque hay oxígenos compartidos que respiramos pueblos a los que nos unió la historia, y que avivan una mentalidad común. Pero las ciudades hoy se han convertido en crisoles de una gran diversidad, donde se fusionan distintas formas y manifestaciones de la cultura. El gran desarrollo demográfico se ha dado además en las ciudades, en las grandes urbes que hoy constituyen, más allá de los Estados, los grandes polos de atracción no solo demográfica sino también económica y, por ende, cultural. De ahí la importancia de la cultura como motor de desarrollo, y el acierto que supone poner énfasis en el trinomio cultura local, democracia y desarrollo, tres ámbitos sobre los cuales han de girar las políticas públicas que en la actualidad pretendan construir sociedades más justas y equilibradas. Y que constituyen, a nuestro entender, una de las grandes conclusiones del informe de la Fundación Alternativas y del Observatorio de Cultura y Comunicación que dirige Inmaculada Ballesteros.

Según datos presentados por Enrique Bustamante en dicho informe, en 2018 la aportación de las actividades culturales al PIB mantenía aún «tres décimas de pérdida respecto al año 2008 en cultura $(2,8 \%)$ y dos décimas al añadir la propiedad intelectual (3,5\%)» (Bustamante, 2019: 22); que no era incompatible con la existencia de indicios de recuperación y de crecimiento respecto a los inicios de la crisis anterior, aunque estos fluctuaran dependiendo de los indicadores.

Así, se podía observar una recuperación empresarial clara entre 2008 y 2018, superando el número de entidades mercantiles en 2018 a las existentes una década atrás. El empleo cultural, sin embargo, aún no alcanzaba el nivel alcanzado en 2008, a pesar de la recuperación experimentada; se mantenía la misma desigualdad proporcional del empleo femenino frente al masculino (39\% frente al 61\% aproximadamente); y la precariedad del sector por la alta 
proporción de no asalariados (30,1\% en 2018). Todo ello consecuencia del recorte del gasto público en cultura, que nunca ha regresado a las inversiones de 2008 , tanto por parte del Estado como de las comunidades autónomas, si bien las administraciones locales representaban en 2016 un 64,2\% de la inversión pública en cultura. En cuanto al mercado cultural español privado la recuperación ha sido lenta hasta 2016, con una ligera inflexión a la baja en 2017. Finalmente, siempre según la fuente utilizada, hay que constatar el descenso entre 2016 y 2017 del gasto medio cultural por persona y hogar (Bustamante, 2019, 22) ${ }^{6}$. En definitiva, asistimos durante los años anteriores a la crisis actual a una «recuperación dubitativa» (expresión de Enrique Bustamante), que ahora nos sitúa en un escenario de enorme fragilidad para afrontar las consecuencias de la crisis global que en 2020 nos ha traído la pandemia del Covid-19.

\section{A modo de conclusión: la cultura en la encrucijada}

Tras esa «recuperación dubitativa», que parecía iba a devolvernos paulatinamente a la situación anterior a la crisis de 2008, el Informe sobre el Estado de la Cultura en España 2020 nos muestra un panorama regresivo producto de la pandemia, que sitúa a la cultura en una encrucijada, que necesita inexorablemente «un gran plan de reactivación capaz por fin de crear un tejido cultural sostenible por su función y su rentabilidad social, además de económica» (Bustamante, 2020, 13). A inicios del pasado año la situación de la cultura española presenta, según Enrique Bustamante (2020, 14-17), una serie de debilidades persistentes, que el citado autor enumera como sigue: 1. Gasto privado insuficiente; 2. Gasto público desplomado; 3. Desigualdades de acceso; 4. Debilidades intra e intersectoriales; 5. Precariedad y desequilibrios en la producción y el empleo; y 6. Digitalización insuficiente y desequilibrada. Un repertorio de debilidades ${ }^{7}$, en suma, que dibuja una crisis estructural del sector con evidentes repercusiones sobre el mismo, pero también sobre el conjunto de la actividad económica.

Pero la cultura también puede ayudarnos a salir de la crisis actual. Así lo explica Rausell-Köster (2013) cuando habla de la necesidad de redefinir las políticas culturales para que éstas puedan contribuir, además de satisfacer los derechos culturales de los ciudadanos,

\footnotetext{
${ }^{6}$ Los datos que acabamos de exponer se detallan de manera pormenorizada en: Bustamante Ramírez, E. (2019): Introducción. Tiempos convulsos, también para la cultura. En Bustamante, E. (Coord.) (2019): Informe sobre el estado de la cultura en España, 2019. Cultura local, democracia, desarrollo. Madrid: Fundación Alternativas, pp. 21-23.

${ }^{7}$ La serie de debilidades que se citan se explican ampliamente en: Bustamante Ramírez, E. (2020): Introducción. Entre dos crisis (2011-2020). Naufragios y esperanzas culturales para el futuro próximo. En Bustamante Ramírez, E. (Coord.) (2020): Informe sobre el estado de la cultura en España, 2020. La acción cultural exterior de España. Análisis y propuestas para un nuevo enfoque. Madrid: Fundación Alternativas, pp. 14-17.
} 
a la transformación económica y social ${ }^{8}$. Pero además porque puede también ayudarnos a reconstruirnos como individuos. Las grandes crisis afectan a todos los órdenes de la existencia, a nuestra vida social y a nuestro espacio de convivencia, pero también a nosotros mismos como personas. Los agentes de la cultura, pese al confinamiento y a la paralización de su actividad, han seguido estando presentes en nuestro entorno, comprometidos con la sociedad y con el ciudadano desde su propio trabajo creativo, y mostrando la importancia social del mismo. Ojalá en esta encrucijada vital, por la que también atraviesa la cultura, las políticas públicas que nuestros gobernantes pongan en marcha para salir de la crisis actual contemplen por fin que la cultura es un factor imprescindible en el proceso de reconstrucción de la sociedad.

\section{Referencias bibliográficas}

Álvarez Fernández, Jesús Timoteo (1987): Historia y modelos de la comunicación en el siglo XX: el nuevo orden informativo. Barcelona: Ariel; y (2012): Historia y modelos de la comunicación en el siglo XX: con proyecciones al siglo XXI. Madrid: Universitas.

Bustamante Ramírez, Enrique (Coord.) (2019): Informe sobre el estado de la cultura en España, 2019. Cultura local, democracia, desarrollo. Madrid: Fundación Alternativas; (2019): Introducción. Tiempos convulsos, también para la cultura. En Bustamante Ramírez, Enrique (Coord.) (2019): Informe sobre el estado de la cultura en España, 2019. Cultura local, democracia, desarrollo. Madrid: Fundación Alternativas, pp. 17-28; y (Coord.) (2020): Informe sobre el estado de la cultura en España, 2020. La acción cultural exterior de España. Análisis y propuestas para un nuevo enfoque. Madrid: Fundación Alternativas, y (2020): Introducción. Entre dos crisis (2011-2020). Naufragios y esperanzas culturales para el futuro próximo. En Bustamante Ramírez, Enrique (Coord.) (2020): Informe sobre el estado de la cultura en España, 2020. La acción cultural exterior de España. Análisis y propuestas para un nuevo enfoque. Madrid: Fundación Alternativas, pp. 11-25.

Carreras Ares, Juan José \& Forcadell Álvarez, Carlos (Eds.) (2003): Usos públicos de la Historia. Zaragoza/Madrid: Prensas Universitarias de Zaragoza/Marcial Pons.

Castro Higueras, Antonio (2017): Las Industrias Culturales y Creativas y su Índice de Potencialidad. Salamanca: Editorial Comunicación Social; y Castro Higueras, Antonio \& Pérez Rufí, José

\footnotetext{
8 Un ejemplo de ello se puede encontrar en: Castro Higueras, Antonio \& Pérez Rufí, José P. (2021): Cultura, tecnología y urbanismo: las bases para construir una ciudad global. El caso Málaga. Revista Mediterránea de Comunicación, 12 (1), pp. 65-76.
} 
P. (2021): Cultura, tecnología y urbanismo: las bases para construir una ciudad global. El caso Málaga. Revista Mediterránea de Comunicación, 12 (1), pp. 65-76.

Childe, Vere Gordon (1995): Los orígenes de la civilización. México: FCE, 21ª reimpr.

García Galindo, Juan Antonio (1995): Andalucía en el proceso de conformación de la sociedad/cultura de masas. Anales de Historia Contemporánea, 11, págs. 233-245; y García Galindo, Juan Antonio et al. (2017): Las industrias culturales y creativas en Andalucía: grandes datos. Barcelona: Portal Localcom.

Gómez-Mompart, Josep-Lluís (1992): La gènesi de la premsa de masses a Catalunya. Barcelona: Pòrtic.

Hauser, Arnold [1951] (2010): Historia social de la literatura y el arte. Barcelona: Marcial Pons, 2 vols.

López Garrido, Diego (2019): El desafío de la cultura local y urbana. En Bustamante Ramírez, Enrique (Coord.) (2019): Informe sobre el estado de la cultura en España, 2019. Cultura local, democracia, desarrollo. Madrid: Fundación Alternativas, pp. 9-10.

Martín Barbero, Jesús, Fuentes Navarro, Raúl \& Coelho, Teixeira (2002): La democratización de la cultura. Renglones, 51, mayo-agosto, pp. 121-126.

Ortega y Gasset, José [1930] (1999): La rebelión de las masas. Barcelona: Austral.

Pérez Gómez, Ángel (2012): Educarse en la era digital. Madrid: Morata.

Raussell-Köster, Pau (2013): Comprender la economía de la cultura como vía para salir de la crisis. El profesional de la información. Vol. 22, 4, pp. 286-289.

Rodríguez Ortega, Nuria (2020): Inteligencia artificial y campo del arte. Paradigma, 23, marzo, pp. 32-51.

Sassoon, Donald (2006): Cultura. Elpatrimonio común de los europeos. Barcelona: Crítica.

Toffler, Alvin [1970] (1995): El shock del futuro. Barcelona: Plaza y Janés.

Zallo, Ramón (2019): En el contexto de los cambios socioeconómicos y políticos: objetivos y desafíos de las políticas culturales locales. En Bustamante Ramírez, Enrique (Coord.) (2019): Informe sobre el estado de la cultura en España, 2019. Cultura local, democracia, desarrollo. Madrid: Fundación Alternativas, pp. 41-53. 